\title{
Imuno-histoquímica para identificação de células neoplásicas no infiltrado ativo de melanomas finos
}

\section{Immunohistochemistry for identification of neoplasic cells within brisk infiltrate of thin melanomas}

\author{
Ana Gabriela Salvio'; Mariângela Esther Alencar Marques²
}

\begin{abstract}
unitermos resumo
Melanomas finos

Melanoma in situ

Melan-A

Imuno-histoquímica!

Melanomas finos freqüentemente apresentam infiltrado linfocitário ativo. Melonócitos pigmentados e melanófagos dispersos no infiltrado linfocitário ativo são difíceis de se distinguir nas colorações de rotina, em lâminas coradas pela hematoxilina eosina $(\mathrm{HE})$. A presença de melanócitos na derme papilar caracteriza a lesão como Clark II exigindo medida de Breslow, o que justifica a importância de vencer essas limitações técnicas. Mesmo usando técnica de imuno-histoquímica com Melan-A e diamino benzidina (DAB) como cromógenos, essa distinção é ainda difícil. O pigmento marrom formado pelo cromógeno $D A B$ não pode ser facilmente diferenciado dos grânulos marrons do pigmento de melanina. Nós introduzimos uma simples modificação na técnica, substituindo a contracoloração de hematoxilina pelo Giemsa. Com essa modificação, o pigmento de melanina foi corado em azul-esverdeado, contrastando com a coloração positiva pelo Melan-A dos melanócitos, que permaneceu marrom. Macrófagos negativos para Melan-A continham apenas grânulos grosseiros azul-esverdeados no citoplasma. Assim, fomos capazes de identificar com precisão células Melan-A positivas na derme papilar, determinando microinvasão (Clark II) em 31 (75,5\%) dos 40 casos de melanomas in situ (Clark I) associados com infiltrado linfocitário ativo. A técnica apresentada permite, portanto, diferenciar macrófagos e melanócitos dispersos no infiltrado linfocitário associado a melanomas finos, permitindo detectar invasão inicial, evitando interpretação errônea do nível de Clark e da medida de Breslow.
\end{abstract}

\section{abstract}

Thin melanomas are frequently associated with brisk lymphocytic infiltrate. Pigmented melanocytes are difficult to distinguish from melanophages, which are usually seen interspersed among lymphocytes on routine hematoxylin and eosin (HE) stained slides. As the presence of melanocytes in the papillary dermis characterizes the lesion as Clark II requiring the Breslow index, it is important to identify these cells properly and overcome such technical limitations. Even using immunohistochemistry staining for Melan-A and DAB as chromogens, this distinction is still difficult because the brown pigment formed by the chromogen DBA can not be easily differentiated from the brown melanin granules. We have introduced a simple modification on the technique, by replacing hematoxylin with Giemsa as counterstain. In this regard, the melanin pigment was decorated in green-blue while the Melan-A positive melanocytes were colored brown. Negatively stained melanophages contain only course green-blue granules of melanin in their cytoplasm. Thus, we were able to identify Melan- $A$ positive cells in the papillary dermis accurately, determining microinvasion (Clark II) in 31 (77,5\%) out of 40 in situ (Clark I) melanomas associated with brisk infiltrate. This technique is useful to distinguish melanophages and melanocytes interspersed among the lymphocytic infiltrate associated to thin melanomas, allowing detection of early invasion and avoiding Clark levels and Breslow index misinterpretation. key words

Thin melanomas

In situ melanomas

Melan-A

Immunohistochemistry

1. Médica dermatologista, doutoranda em patologia do Departamento de Patologia Faculdade de Medicina de Botucatu da Universidade Estadual Paulista (UNESP).

2. Professora-assistente-doutora do Departamento de Patologia da Faculdade de Medicina de Botucatu da UNESP.

Trabalho realizado no Departamento de Patologia da Faculdade de Medicina de Botucatu da UNESP. 


\section{Introdução}

Melanomas finos podem apresentar infiltrado linfocitário em atividade na base da lesão, dificultando a visualização dos seus limites ${ }^{(3)}$. A presença de células de melanoma isoladas no infiltrado inflamatório é de difícil caracterização, podendo-se confundi-las com melanófagos na coloração de rotina com hematoxilina eosina $(\mathrm{HE})^{(7,9,12,18)}$. A distinção entre o comprometimento da derme papilar pelo melanoma (nível Il de Clark) e a simples presença de melanófagos é importante para caracterização do melanoma in situ (Clark I) ou microinvasivo (Clark II) $)^{(3,4,16)}$ e da necessidade da medida da espessura de Breslow.

Um dos fatores limitantes na utilização da imuno-histoquímica para identificar células de melanoma no infiltrado linfocitário ativo dessas lesões é a presença de pigmento de melanina tanto nas células melanocíticas como em melanófagos na derme.

O desenvolvimento dos anticorpos anti-Melan-A/Mart1 ampliou os índices de sensibilidade e especificidade da identificação imuno-histoquímica de melanócitos no melanoma ${ }^{(5,8,12,15,18)}$. Esses anticorpos monoclonais reconhecem proteína específica de diferenciação melanocítica, expressa nos melanócitos benignos e malignos, sendo mais sensíveis e específicos que HMB-45 e S-100 $11,5,12,11)$. Contudo, a imunomarcação pelo Melan-A, revelada pela coloração castanha do cromógeno diamino benzidina (DAB), presente no citoplasma das células de melanoma, pode ser confundida com a melanina presente no citoplasma de macrófagos ou mesmo de melanócitos pigmentados. Com o objetivo de evitar esse problema e potenciar a especificidade da imunomarcação pelo Melan-A, propusemos modificação na técnica, com a substituição da contracoloração com hematoxilina de Harris pelo de Giemsa, o qual permitiria distinção com maior precisão entre pigmento melânico e melanina. A melanina presente no citoplasma de macrófagos ou nas células melanocíticas seria evidenciada pela coloração azul-esverdeada com grânulos grosseiros, enquanto a imunomarcação pelo Melan-A continuaria a ser relevada em castanho pelo cromógeno DAB.

\section{Objetivo}

A proposta deste trabalho é enfatizar a simples modificação técnica para a identificação de células Melan-A positivas no infiltrado linfocitário ativo de melanomas finos, utilizando imuno-histoquímica - técnica da estreptavidinabiotina-peroxidase $(A B C)$ e contracoloração pelo Giemsa.

\section{Materiais e métodos}

Foram inclusos no presente trabalho 40 casos de melanoma in situ dos arquivos do Departamento de Patologia do Hospital Amaral Carvalho, hospital de referência oncológica do sistema de saúde pública, localizado na cidade de Jaú-SP. Os casos apresentavam obrigatoriamente infiltrado linfocitário ativo obscurecendo os limites inferiores da lesão. Foram excluídos os casos com nevo melanocítico associado.

Todos os tecidos foram fixados em formalina, incluídos em parafina e corados com hematoxilina e eosina (HE) para o diagnóstico histopatológico. Secções histológicas adicionais foram realizadas para as colorações imuno-histoquímicas.

A coloração imuno-histoquímica foi realizada em cortes histológicos de $4 \mu \mathrm{m}$ de espessura, dispostos em lâminas histológicas previamente tratadas com o aderente poli-D-lisina, seguindo-se a técnica da $A B C$ brevemente descrita a seguir. Foi feita a desparafinação em xilol seguida da hidratação em solução aquosa de álcool etílico e lavagem com água. Após o bloqueio da peroxidase endógena com água oxigenada a $3 \%$ por dez minutos, os cortes histológicos foram colocados em solução de ácido cítrico a $0.01 \mathrm{M}, \mathrm{pH} 6$ e submetidos à temperatura de $121^{\circ} \mathrm{C} \mathrm{em}$ ambiente de microondas por 15 minutos para a recuperação antigênica. Após descanso de 20 minutos, incubou-se o anticorpo primário Melan-A (Clone A103; Dako Corporation SA) na titulação de 1:100 por 18 horas a $4^{\circ} \mathrm{C}$ em câmara úmida. Após a lavagem das lâminas em solução salina tamponada, foram adicionados os reagentes secundário (Biotinilado anti-mouse Ba 2000Vector) e terciário(ABC PK 6100 - Vector), incubando-os por 60 e 45 minutos, respectivamente. A reação foi revelada com DAB (Sigma Co., S. Louis, EUA) por cinco minutos e contracorada com Giemsa. Como controle negativo, omitiu-se o anticorpo primário, não sendo evidenciada nenhuma marcação nos casos avaliados. Cortes histológicos adicionais dos dez primeiros casos foram também corados pela técnica da $A B C$ e Melan-A e contracorados pela hematoxilina de Harris para comparação.

As lâminas coradas por HE e Melan-A foram examinadas ao microscópio óptico comum pelos autores, com o intuito de caracterizar células do melanoma, isoladas ou constituindo pequenos grupamentos, dispersas no infiltrado linfocitário ativo associado ao melanoma.

\section{Resultados}

As lâminas coradas pela HE ofereceram grande dificuldade para a diferenciação segura de eventuais células melanocíticas e melanófagos no infiltrado linfocitário ativo ${ }^{(9,12)}$. A análise das lâminas coradas pelo Melan-A e contracoradas 
pela hematoxilina de Harris também ofereceu dificuldade freqüente na diferenciação do pigmento de melanina e da coloração positiva pelo Melan-A, tornando a decisão muitas vezes impossível ${ }^{(9)}$. Em contraste, as lâminas coradas pelo Giemsa permitiram clara distinção entre melanina corada em azul-esverdeado e imunomarcação para Melan-A revelada pela cor acastanhada do DAB. Essa distinção foi possível mesmo quando os dois pigmentos estavam presentes na mesma célula, ou seja, no caso de melanócitos Melan-A positivos com melanina no citoplasma.

A coloração de Melan-A e Giemsa permitiu identificar células de melanoma, isoladas ou em pequenos grupamentos, dispersas no infiltrado linfocitário ativo em 31 (77,5\%) dos 40 casos estudados.

A Figura 1 mostra exemplo de lâmina corada por Melan-A e hematoxilina de Harris.

As Figuras $\mathbf{2}$ a $\mathbf{5}$ demonstram exemplos de casos estudados. As células foram coradas pelo Melan- $A$, e melanófagos, diferenciados pela técnica do $A B C$. Células MELAN-A positivas apresentam citoplasma corado em marrom acastanhado com grânulos delicados, e as células melanofágicas, citoplasma corado em azul-esverdeado com grânulos grosseiros ${ }^{(9)}$.

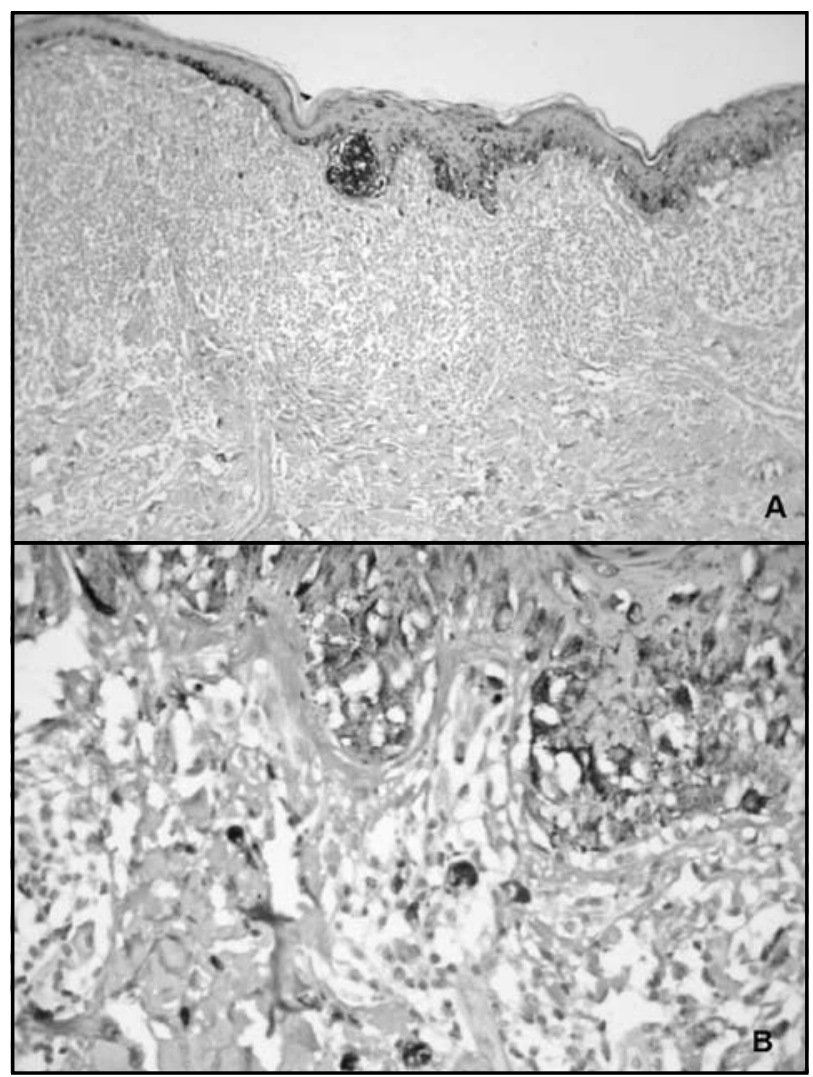

Figura 1 - A: Melanoma fino com infiltrado linfocitário ativo corado pelo MELAN-A, contracorado com hematoxilina de Harris. Evidente dificuldade em distinguir melanócitos e melanófagos dispersos no infiltrado linfocitário; $B$ : detalhe da figura $A$ (imuno-histoquímica técnica do $A B C$ - contracoloração com hematoxilina de Harris 100x; 400x)

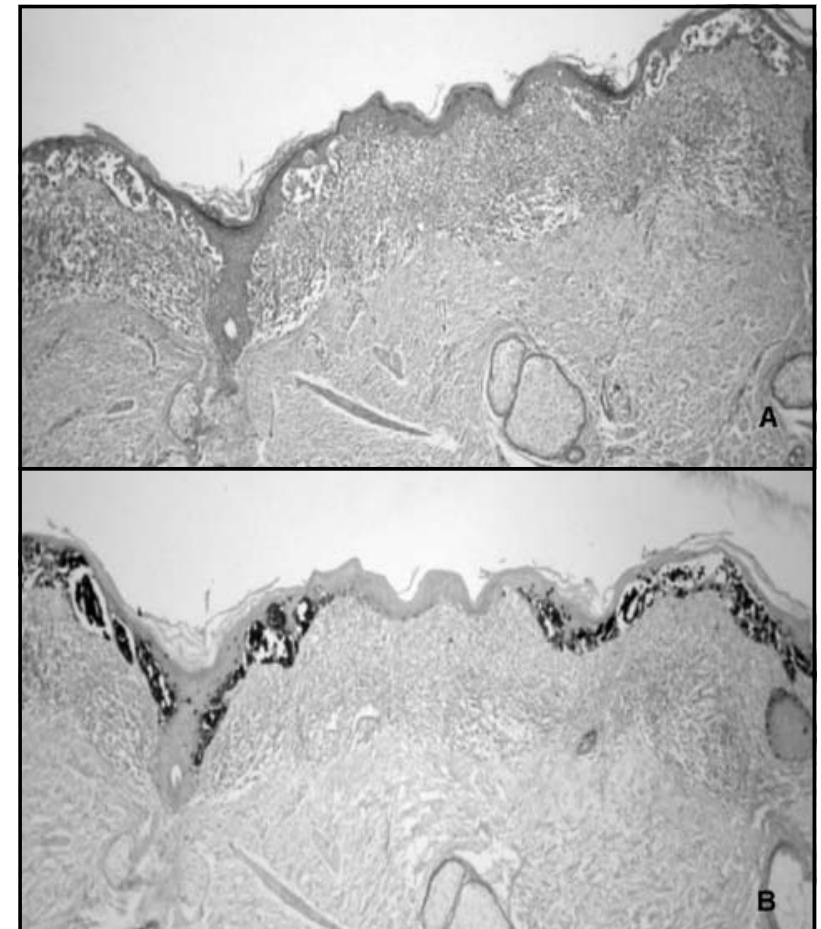

Figura 2 - A: Infiltrado linfocitário ativo dificultando a visualização dos limites do melanoma (HE 50x); B: facilidade na determinação dos limites da lesão com a coloração pelo MELAN-A (imuno-histoquímica técnica da $A B C$ - contracoloração com Giemsa 50x)

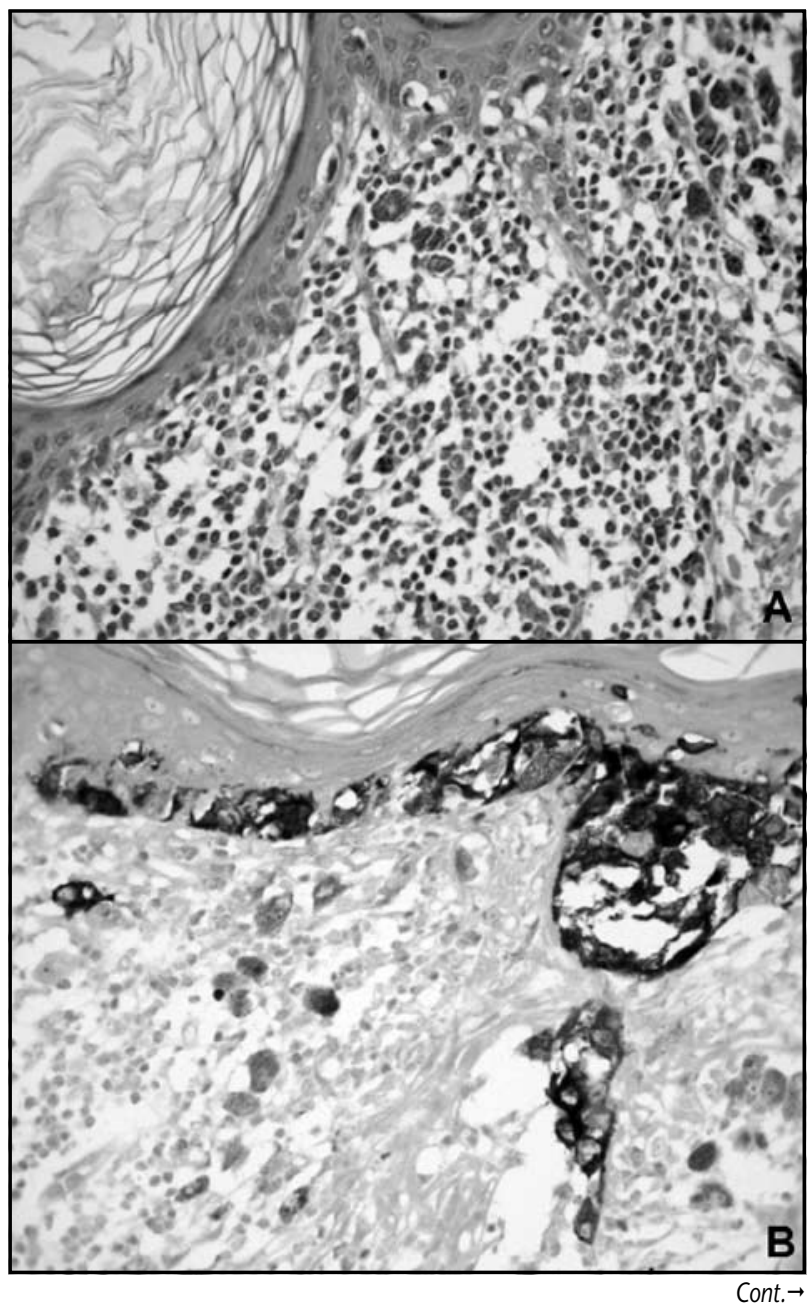




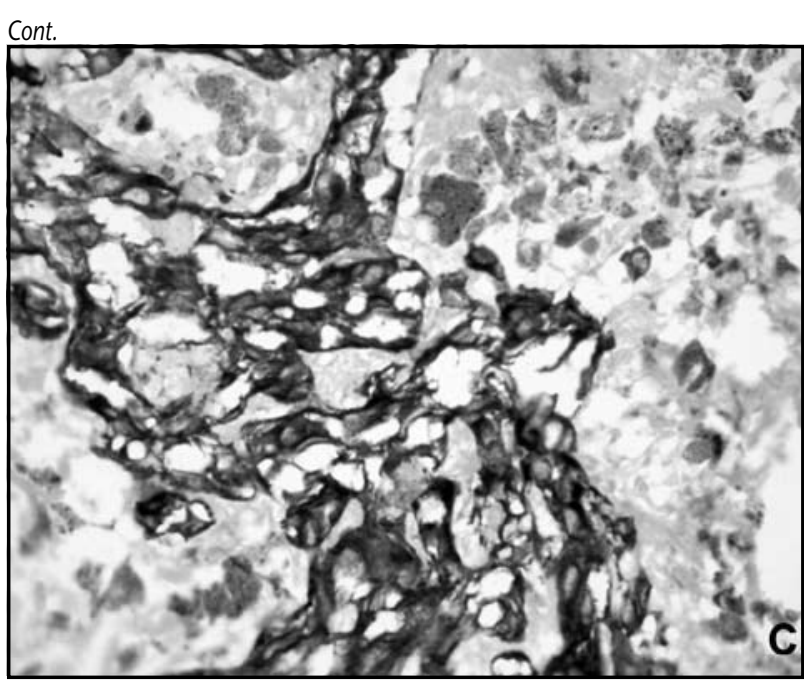

Figura 3 - A: Dificuldade de distinção das células do melanoma no infiltrado linfocitário ativo (HE 400x); B e C: distinção entre célula de melanoma (marrom) e células macrofágicas (azul-esverdeado) (imuno-histoquímica técnica da $A B C$ - contracoloração com Giemsa 400x)

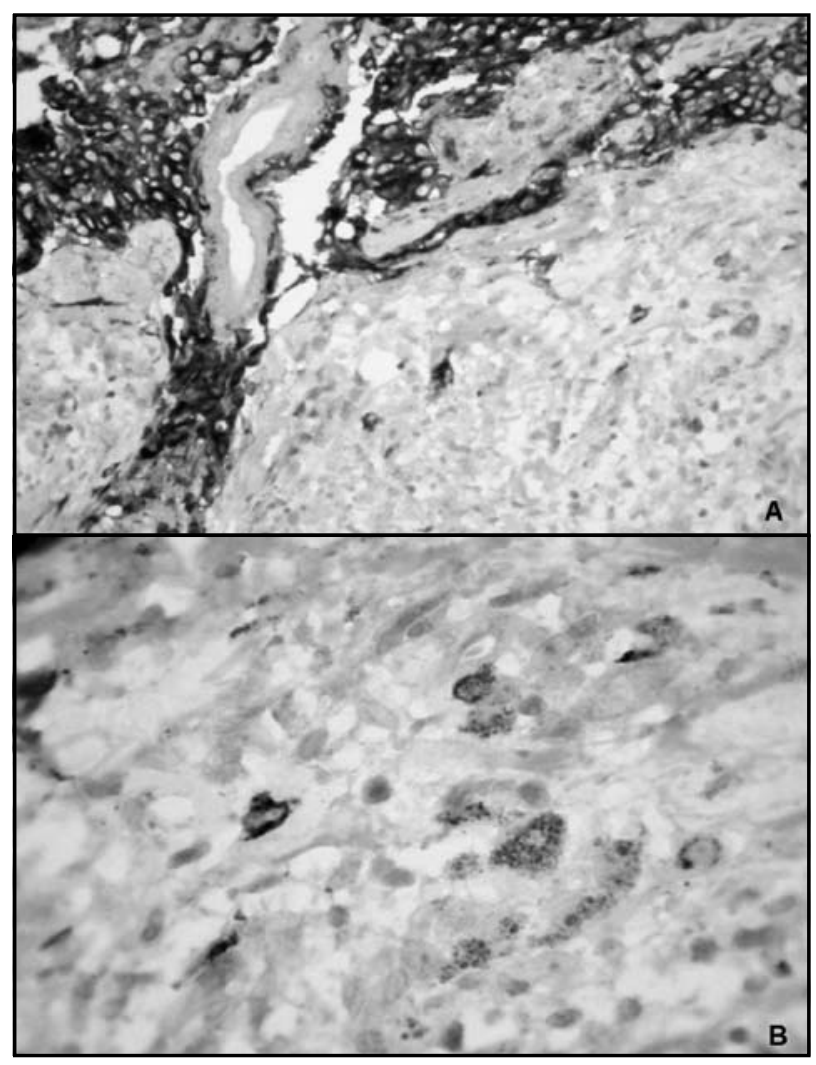

Figura 4 - A: Distinção entre melanócitos (marrom) e melanófagos (azul-esverdeado) (imuno-histoquímica técnica da $A B C$ - contracoloração com Giemsa 400x); B: detalhe da Figura $4 A$ (imuno-histoquímica técnica da $A B C$ - contracoloração com Giemsa 1.000x)

\section{Discussão}

O presente estudo demonstrou que a técnica da $A B C$, utilizando DAB como cromógeno e contracoloração com Giemsa, pode ser utilizada com sucesso para identificar células melanocíticas dispersas em infiltrado linfocitário

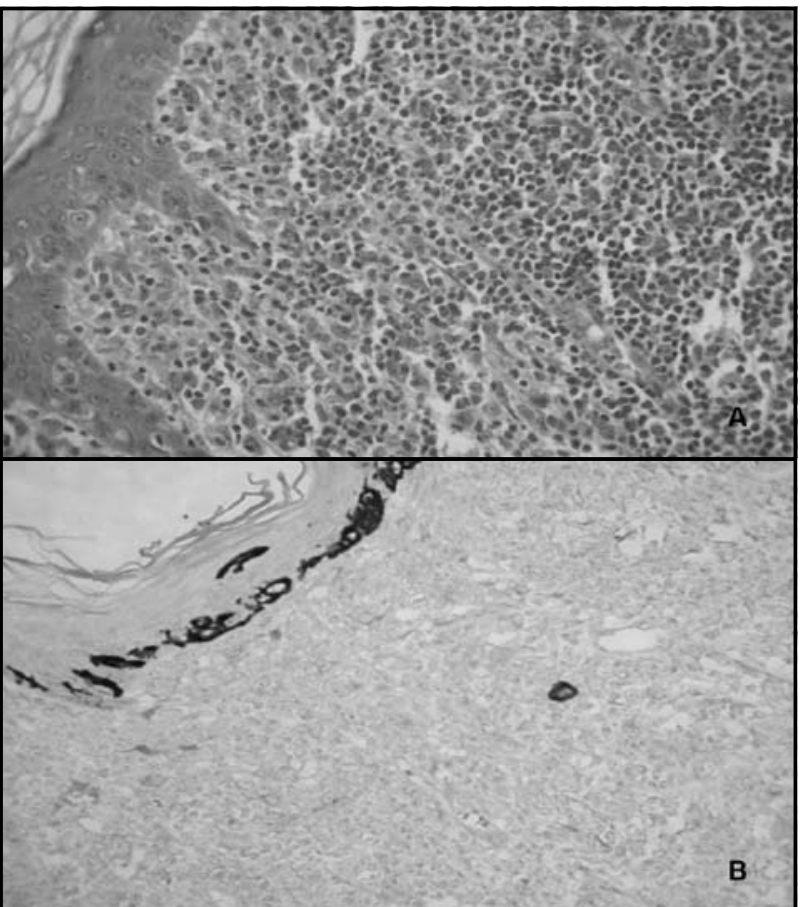

Figura 5 - A: Infiltrado linfocitário ativo dificultando a precisão do nível de invasão dérmico (HE 400x); B: presença de célula melanocítica no infiltrado, identificada pelo MELAN-A (imuno-histoquímica técnica da $A B C$ - contracoloração com Giemsa 1.000x)

de melanomas $(7,12,16,18)$, permitindo clara distinção entre melanófagos e células neoplásicas imunomarcadas com Melan-A. A simples substituição da hematoxilina de Harris pelo Giemsa, introduzida no final da reação, foi responsável pela eficiência do método, corando a melanina em azul-esverdeado e tornando-a inequivocamente distinta da coloração positiva marrom-acastanhada para Melan-A, revelada pelo cromógeno $D A B^{(9)}$. Assim, houve grande facilidade em distinguir melanócitos e macrófagos quando em comparação com outras técnicas utilizadas para estudar neoplasias melanocíticas intensamente pigmentadas $(6,13,17)$. Trata-se, portanto, de importante ferramenta metodológica para a dermatopatologia, pois ainda que os melanócitos pudessem ser imunomarcados com anticorpos bastante específicos ${ }^{(15,19,20)}$ a técnica de imuno-histoquímica mais utilizada na rotina laboratorial, atualmente, é aquela revelada pelo cromógeno $\mathrm{DAB}$, produzindo pigmento marromacastanhado que pode ser confundido com melanina ${ }^{(6)}$.

Em 1991, Kamino e $\operatorname{Tam}^{(9)}$ utilizaram imunoperoxidase, técnica peroxidase-antiperoxidase e contracoloração com Azure $\mathrm{B}$, demonstrando nítida distinção entre o pigmento de melanina e a coloração positiva da imunoperoxidase revelada pelo cromógeno $D A B$, em lesões melanocíticas intensamente pigmentadas. Além disso, outros trabalhos anteriores propuseram modificações do DAB para alterar a 
cor, como a adição de íons metálicos ${ }^{(6)}$, que resultaria em pigmento enegrecido, ou ainda utilização de cromógeno AEC (3-amino-9-etilcarbazol) e fosfatase alcalina, ambos revelados como pigmento vermelho. Ao contrário do $D A B$, que é muito estável e duradouro, produzindo lâminas permanentemente coradas, o pigmento vermelho produzido pelo AEC descora-se com o tempo e exige montagem das lâminas em meio aquoso. O pigmento produzido pela fosfatase alcalina é durável e as lâminas são permanentes, porém o tempo de reação é maior do que o necessário quando se utiliza o DAB.

Com a finalidade de validar a eficácia da metodologia proposta, o presente trabalho realizou pesquisa de células de melanoma no infiltrado linfocitário ativo de 40 casos de melanomas in situ. A técnica utilizada foi a imuno-histoquímica ABC com Melan-A e contracoloração com Giemsa ${ }^{(7,8)}$. Foram identificadas células Melan-A positivas em 31 de 40 casos $(77,5 \%)$ in situ, demonstrando que $77,5 \%$ desses melanomas eram na realidade microinvasivos (Figura 6). Desse modo, podemos dizer que pelos dados do presente trabalho, mais de $70 \%$ dos melanomas in situ estudados agora devem ser submetidos à medida da espessura de Breslow e, portanto, devidamente estadiados $(2,10,14)$.

\section{Conclusão}

A técnica de imuno-histoquímica da $A B C$ e contracoloração pelo Giemsa pode ser utilizada como ferramenta importante na caracterização de células de melanoma Melan-A positivas no infiltrado ativo associado a melanomas, uma

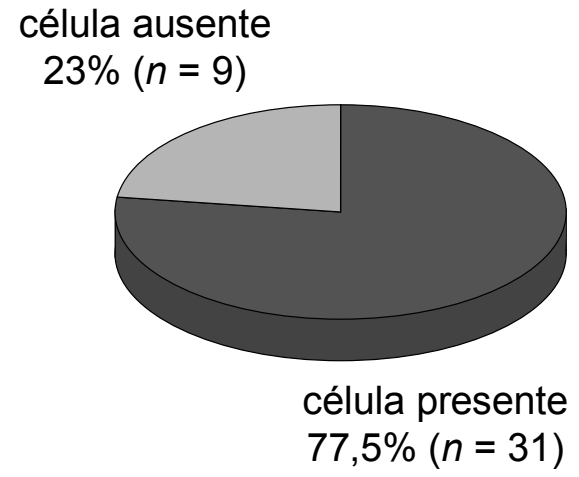

Figura 6 - Distribuição dos 40 casos de melanoma, de acordo com a presença de células MELAN-A positivas, infiltrado com a técnica de imuno-histoquímica

vez que não altera a rotina do laboratório e não necessita cromógeno especial.

\section{Agradecimentos}

Agradecemos ao Dr. Francisco C. Quevedo, ao Dr. Francisco Moraes Neto e ao Dr. Adauto J. Nunes do Serviço de Patologia do Hospital Amaral Carvalho pelo material usado. Agradecimentos à FAPESP pelo auxílio-pesquisa concedido ao estudo, processo no 2003-00145-7. Agradecemos aos técnicos Marcos Roberto Franchi, Celene Maria Carvalho Gandin e José Carlos Pedroso Lima pela padronização da técnica e pela confecção das lâminas. Agradecemos ao Dr. Silvio Alencar Marques e ao Dr. Daniel Araki Ribeiro pela revisão crítica deste manuscrito.

\section{Referências}

I. BERGMAN, R. et al. A comparative immunohistochemical study of MART-I expression in Spitz nevi, ordinary melanocytic nevi and malignant melanoma. J Am Acad Dermatol, v. 42, n. 3, p. 496-500, 2000

2. BRESLOW, A. Thickness, cross-sectional areas and depth of invasion in the prognosis of cutaneous melanoma. Ann Surg v. 172, p. 902-8, 1970

3. CROWSON, A. N.; MAGRO, C. M., MIHN, M. C. Malignant melanoma. In:The melanocytic proliferations: a comprehensive textbook of pigmented lesions. New York: Wiley-Liss, 2001 Cap 10., p. 28I-397.

4. ELDER, D.; ELENITSAS, R. Benign pigmented lesions and malignant melanoma. In: ELDER, D. et al. Lever's histopathology of the skin. $8^{\text {th }}$ ed. Lippincott Raven, 1997. Chap. 29, p. 625-84.

5. GOWN, A. M.; BACCHI, C. E. Diagnostic immunohistochemistry.
In: MEETING UNITED STATES - CANADIANACADEMY OF PATHOLOGY, 2002, Chicago. Proceedings. Chicago, 2002.63p.

6. HSU, S. M.; SOBAN, E. Color modification of diaminobenzidine (DAB) preparations by metallic ions and its application for double immunohistochemistry. J Histochem Cytochem, v 30, p 1079, 1982.

7. JAFFER, S.; BLEIWEISS, I. Beyond hematoxylin and eosin - the role of immunohistochemistry in surgical pathology. Cancer Invest, v. 22, n. 3, p. 445-65, 2004.

8. JUNGBLUTH, A. A. et al. A I03: an anti Melan A monoclonal antibody for the detection of malignant melanoma in paraffin-embedded tissues. Am J Surg Pathol, v. 22, n. 5, p. 595-602, 1998.

9. KAMINO, H.;TAM, S. T. Immunoperoxidase technique modified 
by counterstain with azure $B$ as a diagnostic aid in evaluating heavily pigmented melanocytic neoplasms.J Cutan Pathol, v. I8, p. 436-9, I991.

10. KELLEY, L. C.; STARKUS, L. Immunohistochemical staining of lentigo maligna during Mohs micrographic surgery using MART-I. J Am Acad Dermatol, v. 46, n. I, p. 78-84, 2002.

I I. LOMUTO, M; CALABRESE, A.; GIULIANI, A. Prognostic signs in melanoma: state of the art. Eur Acad Dermatol Venereol, v. |8, p. 29|-300, 2004.

12. MANGINI, J; LI, N.; BHAWAN, J. Immunohistochemical markers of melanocytic lesions. A review of their diagnostic usefulness. Am J Dermatopathol, v. 24, n. 3, p. 270-8I, 2002.

|3. NAD|l, M Immunoperoxidase techniques. Facts and artifacts. Am J Dermatopathol, v. 8, n. I, p. 32, 1986.

I4. ORCHARD, G. E.; CALONJE, E.The effect of melanin bleaching on immunohistochemical staining in heavily pigmented melanocytic neoplasms. Am J Surg Pathol, v. 20, n. 4, p. $357-$ 61, 1998.
15. RAMIREZ-MONTAGUT,T. et al. Melanoma antigen recognition by tumor-infiltrating T lymphocytes (TIL): effect of differential expression of Melan-A/MART-I. Clin Exp Immunol, v. II9, p. I I-8, 2000.

16. RUITER, D. J.; VAN DIJK, M. C. R. F.; FERRIER, C. M. Current diagnostic problems in melanoma pathology. Semin Cutan Med Surg, v. 22, n. I, p. 33-4I, 2003.

17. SCHAUMBURG-LEVER, G. The alkaline phosphatase antialkaline phosphatase technique in dermatopathology. J Cutan Pathol, v. I4, p. 6, 1987.

18. SMOLLER, B. R. Practical Immunopathology of the skin. Totowa: Humana Press, 2002.

19. TAYLOR, C. R. et al. Techniques of immunohistochemistry: principals, pitfalls and standardization. In: DABBS, D. J. Diagnostic immunohistochemystry. Churchill Livingstone, 2002. Chap I. p. 3-44.

20. XU, X. et al. Immunoprofile of MITF, tyrosinase, Melan-A, and Mage- I in HMB45 - negative melanomas. Am J Surg Pathol, v. 26, n. I, p. 82-7, 2002. 